\title{
A Cloud Computing Framework for Quality Based e-Education System
}

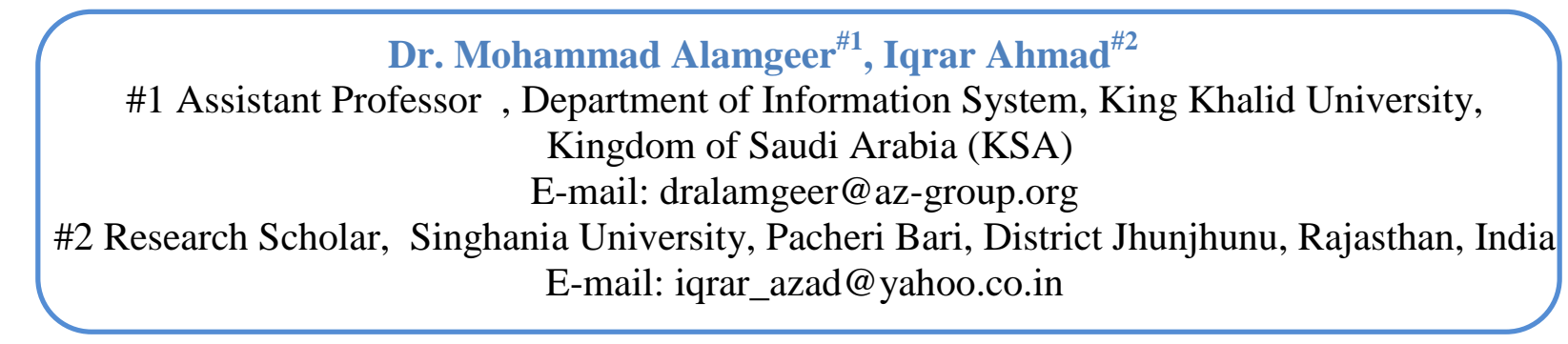

\section{ABSTRACT}

As with rapid growth of the computer technology, there are required a lot of hardware and software resources in cloud based education. There are many educational institutions that can't afford the huge amount of such investments. Cloud computing is an excellent option for educational institutions which are mainly under budget which are not capable to operate their information systems effectively without spending any more money for the software and hardware devices. It will likely have a significant impact on the educational environment in the future. This computing approach relies on a number of existing technologies such as the cluster computing, grid computing, virtualization, web services etc. This paper proposes a model of cloud computing for modern e-education system. The basic concept for designing the system is to build the cloud computing based e-Education services environment for e-learning and eresearch. In this paper, we will review what the cloud computing infrastructure will provide in the educational arena, especially in the universities where the use of computers are more intensive and what can be done to increase the benefits of common applications for students and faculties.

Keywords: E-learning, cloud computing, modern e-education, cloud based framework

\section{Corresponding Author: Iqrar Ahmad}

\section{INTRODUCTION}

The incredible enhancement in the internet technologies during the last couple of decades has changed the way students thinking, learning and working style. E-education based on cloud provides the worthy content and knowledge as that of traditional learning environment provide. Many hardware and software resources are required in cloud based education. There are many educational institutions that can't afford the huge amount of such investments. So, therefore, cloud platform is the best solution for e-education. Cloud computing is a large-scale distributed computing paradigm that is driven by economies of scale, in which a pool of abstracted, virtualized, dynamically-scalable, managed computing power, storage, platforms, and services 
DOI: https://dx.doi.org/10.26808/rs.ca.i8v2.18

are delivered on demand to external customers over the Internet. A user on the Internet can communicate with many servers at the same time and these servers exchange information among themselves [1]. The Demand of cloud computing in Commercial increases needs as infrastructure, platform, application, and software services that are growing with complexity and capability. Due to increase a number of users, services, educational contents and resources, and hence some educational institution have needs to reduce the development, operating and maintenance costs. It's an economic force, prompting institution heads to think about the new cloud environment, and some even testing cloud service and data storage to student e-mail, data recovery, or virtual computing labs in the marketplace Due to low infrastructure costs of educational cloud, institution more focuses on resources to improving teaching and learning outcomes. [2]. Both faculties and students can share their educational experiences. Rising cloud demands are forcing developer to consider new ways to reallocate their limited internal resources to better support their business priorities. Today's cloud platforms such as ownCloud, cloudpro, google etc are providing services to students and staff at educational institutions which include file sharing, email, contact lists, developing the websites, data storage etc. [3].

\section{CLOUD COMPUTING FOR E-EDUCATION}

Cloud computing is an excellent alternative for colleges or institutions which are under budget and are failed to transform from traditional learning to e-learning. These colleges or institutions do not have the resources and infrastructure needed to run best e-learning solution effectively [4]. The internet giant Colleges advantages of available cloud-based applications offered by service providers and enable their own students to benefit from a set of online productivity tools and applications in the cloud such as email, calendars, photo sharing, contact lists, document storage, creation and sharing documents etc [5].

IBM's Cloud Burst is a pre packaged cloud that includes hardware, software, applications, and middleware for faster application development and deployment turnaround time [6].

Google is one of the most well-known companies offering software as a free online service to billions of users across the world for example Google Apps, Google Maps and Gmail are all based in the cloud where billions of people are connecting [7].

Cloud computing is a perfect system of low cost and powerful computing capability. By using of SAAS, PAAS, IAAS etc. and higher business models, this powerful computing power has been spread to the hands of end users. Some of the basic cloud computing technologies in e-education are as follows

- Infrastructure as a Service (IaaS): Products offered via this mode include the remote delivery of a full computer infrastructure (e.g., virtual computers, servers, storage devices, etc.)[8].

- Platform as a Service (PaaS): Under this layer, one needs to remember the traditional computing model where each application managed locally required hardware, an operating system, a database, middleware, Web servers, and other software [8]. One also needs to remember the team of network, database, and system management experts that are needed to keep everything up and running. With cloud computing, these services are now provided remotely by cloud providers under this layer.

- Software as a Service (SaaS): In this layer applications are delivered through the medium of the Internet as a service. Instead of installing and maintaining software, you simply access it via the Internet, freeing yourself from complex software and hardware management. This type of cloud service provides a complete application functionality that ranges from office type applications to programs such as those for enterprise-resource management [9]. 
DOI: https://dx.doi.org/10.26808/rs.ca.i8v2.18

- Virtualization technology. Virtualization plays very important role in e-education cloud computing. Virtualization technology can expand the capacity of the hardware, simplifying the software reconfiguration process. CPU virtualization technology allowing a platform to run multiple operating systems and applications can run independent of each other significantly improve equipment efficiency. We can solve some of the server overload by using information technology in e-education [10].

- Security technology. There is the world's most highly developed data center to help us save the data, with a reliable security technology to help us manage our data and programs [11].

For example, in Fig.1 students, instructors, researchers administration can be made to use the services of providers of SaaS and IaaS clouds. PaaS cloud can be used by developers and administration. Software uploaded by the peoples resides on the servers of the SaaS cloud provider and is accessed through Internet. Any requirement for disk space or additional hardware is executed immediately online by the IaaS cloud provider. Developers used these software's as per need for their online development. Cloud computing in e-education is an innovation that it combines and integrates existing technologies and approaches such as distributed computing, utility computing and centralized data centers $[12,13]$.

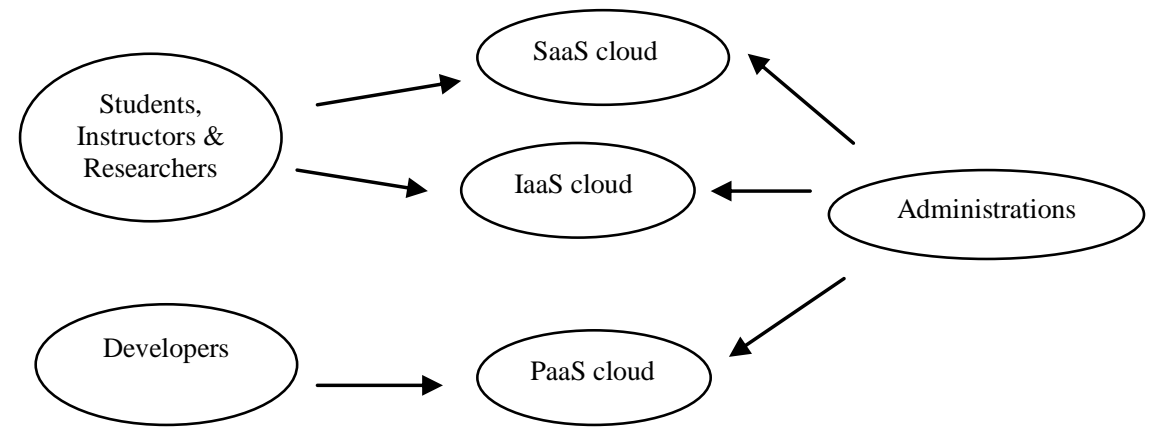

Fig. 1

\section{FEATURES AND ADVANTAGES OF E-EDUCATION CLOUD COMPUTING}

Advances in technology offer new opportunities in enhancing teaching and learning so cloud computing has a significant impact on the educational environment. The features of Cloud computing are as follows:

1. High resources availability: It provides real-time configuration, allocates resources ondemand and improves the usage rate of available resources [14].

2. Super computing power: It makes the support of varies of applications convenient and fast to retrieve the powerful computing and storage resources [14].

3. Crash recovery: If your devices are crashes, no data lost because this data is stored in the cloud [15].

4. Convenience: It is not necessary to download software and data. You can access cloud services anytime and anywhere through Internet [16]. Cloud allows students to work from multiple Places such as college, home, office etc, find their files and edit them. Also browser- 
DOI: https://dx.doi.org/10.26808/rs.ca.i8v2.18

based applications can also be accessed through various devices such as mobile, tablet, laptop and desk top computers etc [17].

5. Security: Cloud manages information by a team of professional. It facilitates strict rights management strategy during accessing data [14].

6. Economic efficiency: There is no need buying expensive hardware for cloud computing and then the education platform could be easily established. Get the most out of efficiency of hardware and software. It provides a low cost solution to academic institutions for their researchers, faculty, clerk and students [18].

7. Virtualization: Each application deployment environment and physical platform is managed, expensed, migrated, and backup through virtualization platform [10].

8. Flexibility: Cloud computing allows user to dynamically scale as demands vary. Scale infrastructure to take full advantage of investments [19].

\section{CHALLENGES FOR E-EDUCATION CLOUD COMPUTING}

Supplier is responsible for developing the system on demands made by users (students, staff, administration etc), which leads marketable value of e-education cloud computing. There are three levels services provided in cloud computing, namely, IaaS, PaaS, and SaaS. As e-learning cloud computing is a new thing for students, staff, administration etc, which faces a lot of challenges [20, 21]. Following are some challenges for e-education cloud computing in its popularity and successes. We should face up to these challenges and find more solutions for them, e-education cloud computing will get a huge development.

Challenges for e-education cloud computing

1) Bandwidth: E-education using cloud computing is totally based on internet. There is need of very high bandwidth for supporting heavy applications. But at present bandwidth is clearly insufficient at many places.

2) Security: When any institutions save the data to equipment afforded by cloud computing service provider, the priority accessing to the data is not the owner, but cloud computing service provider. Because of this, there are very little chances that confidential data may be lost or leak.

3) Educational methods: E-education cloud challenges traditional educational methods. There is only a updating for technology, concepts and tools, giving new content, concepts and methods for education, and hence e-education can't completely replace teachers.

4) Charge: It is one of the challenges how to impose the charge on colleges or any institution for the solution of the problem.

5) Resource development: There are a lot of e- education cloud materials of high quality which requires investing a lot of human and material resources and using the intelligence of educational experts and technical experts in support to create a set of scientific and interesting learning resources.

6) Education management rules: Due to differences between traditional education and eeducation based on cloud, the beginning of e-education cloud computing came with a lot of new problems.

\section{SOLUTIONS FOR E-EDUCATION CLOUD COMPUTING}

Following are the proposed solutions for e-education cloud computing. Hopefully, by applying these, e-education cloud computing will get a vast development.

1) For increase the Bandwidth it better to use fiber optic and leased line for Internet. 
DOI: https://dx.doi.org/10.26808/rs.ca.i8v2.18

2) For security point of view uses encryption technology is much better option for storage and transmission.

3) Design a best learning pattern programs and promote them.

4) It is one of the solutions to impose the charge, divide the charges into two categories: institutions charging for general needs and individual charging for special needs.

5) There is big need to update the technology with new concept to overcome traditional teaching methods.

6) Set up a management rules for e-education based on cloud, such as course management, teaching material management, examination management, student attendance management, teaching workload management etc.

\section{A CLOUD COMPUTING FRAMEWORK FOR QUALITY BASED E-EDUCATION} SYSTEM

Existing infrastructure needs to be revamped with new systems due to change in technology. To support the new trend of software, hardware needs to be upgraded every four or five year's time depending on the type of application. Universities applications are shared network where the university data, learning materials are accessed in the university premises. Users require such a system which has very high super computing power, secure, economically efficient, flexible etc. to carry out teaching, learning and research activities with high end computational power. A framework based on cloud computing for modern e-Education, can be introduced in Fig. 2; it consists of three main clouds: E-education view cloud, E-education internal cloud and Eeducation external cloud. These clouds interoperate with each other. Also cloud can interoperate with social services, enterprise apps such as ERP, etc and consumer apps such as Blackboard, etc. To show how these clouds provide valuable services, it can be illustrate as the policy manager provides the cloud's access facilities. It's main function to examine the security scope of authentication and authorization. The service engine plays very significant role in modern eEducation Cloud. It's main task is to handle services' management. Arriving requests are delegated to VM schedulers or storage masters that manage the computing or storage resources respectively, synchronized by the service engine. The policy manager saved the requirements specified by the clouds. The VM scheduler jobs are allocating, managing and distributing a job for the consequent service. The local computing resources are control by service monitor as per the needs negotiated with the external cloud. Data split into chunks of fixed or variable size. Data chunks are physically stored on chunk providers in hierarchical form. These chunks indexing through file indexes on the storage masters. The storage master directly interfaces with the service engine to discover the resources storing data. External cloud with the help of service engine can get storage service from the internal e-Education cloud. The internal cloud used session controller to authenticate the user credentials of the received service request. Also session controller assigns the valid session identifier to the given user request and retains the session information into the database. The service signature is a XSL template file that contains the attributes such as interface name, endpoint name, function name and the service request data mapping rules. The user requests are mapped to the requested task's service signature by the task request binder. Then, request binder converts the view cloud request parameters into the task service model data transfer object interface [22]. Task Controller Endpoint EJB accepts the service request from the external cloud over the Web services [23]. The Task Service Model encapsulates endpoint service objects which implement the actual task definition so that any eLearning Task such as Lecture, quiz, Test, examination, assignments etc. can be defined in the 
form of Java Bean as a service into the Task Service Container [24]. The View Cloud is a Graphical User Interface to communicate with end client users' accessories such as laptop, mobile, tablet etc.

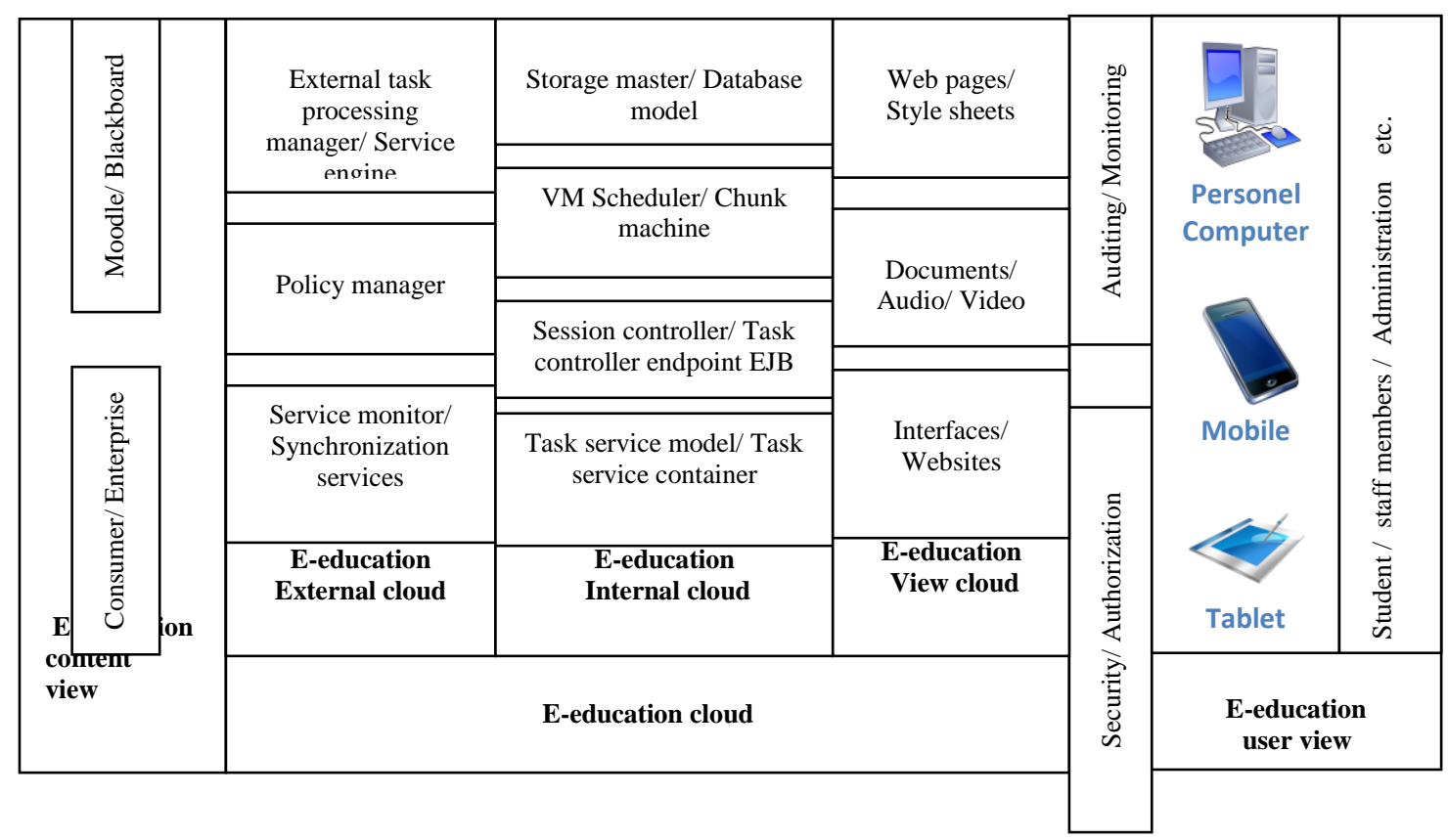

Fig.2. A Cloud Computing Framework for Quality Based E-Education System

\section{CONCLUSION}

Cloud computing playing a significant role in today's e-education system. It provides rapidly and economically accesses various application platforms and resources through the web pages ondemand to the student, staff and administration. This reduces the cost of organizational expenses and offers more powerful functional capabilities. This paper presents a variation of existing eeducational cloud framework. In this paper we discussed interoperability of a framework in eeducation area. On the basis of the above analysis, cloud computing technology based framework is a promising trend for improvement of various indicators of e-education, such as accessibility, economically, quality and management of resources etc. Finally, the level of eeducation will be improved significantly and economically.

\section{References}

[1] https://resources.sei.cmu.edu/asset_files/WhitePaper/2010_019_001_29025.pdf.

[2] Weiss, A.: Computing in the clouds. ACM netWorker 11(4), 16-25 (2007).

[3] Cloudworks, eLearning in the Cloud, http://cloudworks.ac.uk/cloud/view/2430/

[4] T. E. "Effective Use Of Cloud Computing In Educational Institutions". January 5, 2010, Turkey, from Elsevier Ltd.

[5] http://www.infoworld.com. what cloud computing really means. By Eric-Knorr and G. Grurnan.

[6] http://www.ibrn.comlibrnlcloudlcloudburstl. IBM Smart Business Systems.

[7] http://code.google.com, Google App Engine 
DOI: https://dx.doi.org/10.26808/rs.ca.i8v2.18 International Journal of Computer Application (2250-1797)

Issue 8 Volume 2, March-April 2018

[8] The four benefits of cloud computing, Sina science and technology, http://www.cloudcomputing china.cn/Article/jh/200811/218.html, November 13, 2008

[9] On the future technology trends: the development of cloud computing security, http://stor.zol.com.cn/128/1288536.html April13,2009 (reproduced)

[10] http://www.ijstr.org/final-print/nov2014/A-Study-On-Virtualization-Techniques-AndChallenges-In- Cloud-Computing.pdf

[11] http://airccse.org/journal/nsa/6114nsa03.pdf

[12] Business models in the service world. IT Professional, 11(2), 28-33.

[13] Market-oriented cloud computing: Vision, hype, and reality of delivering IT services as computing utilities. In The 10th IEEE international conference on high performance computing and communications (pp. 5-13).

[14] Zhang Guoli and Liu Wanjun, The Applied Research of Cloud Computing Platform Architecture In the E-Learning Area, Proceedings of the 2nd IEEE International Conference on Computer and Automation Engineering 2010, Singapore, pp. 356-359, February 26-28, 2010.

[15] Pocatilu, P., F. Alecu, et al. "Measuring the Efficiency of Cloud Computing for E-learning Systems", Romania January 2010.

[16] http://www.dontwasteyourtime.co.uk, Benefits of Collaborative Learning. Jul 8 .By David Hopkins.

[17] A1-Zoube, M., S. A. EI-Seoud, et al. "Cloud Computing Based ELearning System". "International Journal of Distance Education Technologies (UDET)", 2010, S(2).

[18] http://www.rnicrosofi.com.Cloud computing For Education.

[19] T. E. "Effective Use Of Cloud Computing In Educational Institutions". January 5, 2010, Turkey, from Elsevier Ltd.

[20] Liang Bing, "E-learning and modern education reform", Education Information, 2001.10, pp.21, 25

[21] HU Xin-ping, ZHANG Zhi-mei , DONG Jian, "Medical Informatization Based on Cloud Computing Concepts and Techniques", JOURNAL OF MEDICAL INFORMATICS, 2010, Vol.31, No.3, pp.6-9

[22] T. Erl, Service-Oriented Architecture Concepts, Technology, and Design Prentice Hall PTR, Indiana, US, December 2006.

[23] Tang Jian, Fu Lijian, Gong Tao, "Cloud computing-based Design of Network Teaching System”, Journal of TaiYuan Urban Vocational college, Mar. 2010, pp.159-160

[24] YAO Juan, SUN Yi-xiang, "The Initial Idea of New Learning Society which Based on Cloud Computing”, Modern Educational Technology, Vol.20, No.1, 2010, pp.14-17 